\title{
Effect of Exercise on Blood Pressure in Type 2 Diabetes: A Randomized Controlled Trial
}

\author{
Devon A. Dobrosielski, $P h D^{7}$, Bethany Barone Gibbs, PhD², Pamela Ouyang, MBBS , \\ Susanne Bonekamp, DVM 3 , Jeanne M. Clark, MD ${ }^{4,5}$, Nae-Yuh Wang, $P h D^{4,6}$, \\ Harry A. Silber, $M D P h D^{7}$, Edward P. Shapiro, $M D^{7}$, and Kerry J. Stewart, EdD ${ }^{7}$
}

\begin{abstract}
'Department of Medicine, Division of Cardiology, The Johns Hopkins School of Medicine, Baltimore, MD, USA; ${ }^{2}$ Department of Health and Physical Activity, University of Pittsburgh, Pittsburgh, PA, USA; ${ }^{3}$ Department of Radiology, The Johns Hopkins School of Medicine, Baltimore, MD, USA; ${ }^{4}$ Department of Medicine, Division of General Internal Medicine, The Johns Hopkins School of Medicine, Baltimore, MD, USA;

${ }^{5}$ Department of Epidemiology, The Johns Hopkins Bloomberg School of Public Health, Baltimore, MD, USA; ${ }^{6}$ Department of Biostatistics, The Johns Hopkins Bloomberg School of Public Health, Baltimore, MD, USA.
\end{abstract}

BACKGROUND: Increased blood pressure (BP) in type 2 diabetes (T2DM) markedly increases cardiovascular disease morbidity and mortality risk compared to having increased BP alone.

OBJECTIVE: To investigate whether exercise reduces suboptimal levels of untreated suboptimal BP or treated hypertension.

DESIGN: Prospective, randomized controlled trial for 6 months.

SETTING: Single center in Baltimore, MD, USA.

PATIENTS: 140 participants with T2DM not requiring insulin and untreated SBP of 120-159 or DBP of 85$99 \mathrm{mmHg}$, or, if being treated for hypertension, any SBP $<159 \mathrm{mmHg}$ or DBP <99 mmHg; 114 completed the study. INTERVENTION: Supervised exercise, 3 times per week for 6 months compared with general advice about physical activity.

MEASUREMENTS: Resting SBP and DBP (primary outcome); diabetes status, arterial stiffness assessed as carotid-femoral pulse-wave velocity (PWV), body composition and fitness (secondary outcomes).

RESULTS: Overall baseline BP was $126.8 \pm 13.5$ / $71.7 \pm 9.0 \mathrm{mmHg}$, with no group differences. At 6 months, BP was unchanged from baseline in either group, BP $125.8 \pm 13.2 / 70.7 \pm 8.8 \mathrm{mmHg}$ in controls; and $126.0 \pm 14.2 / 70.3 \pm 9.0 \mathrm{mmHg}$ in exercisers, despite attaining a training effects as evidenced by increased aerobic and strength fitness and lean mass and reduced fat mass (all $\mathrm{p}<0.05$ ), Overall baseline PWV was $959.9 \pm 333.1 \mathrm{~cm} / \mathrm{s}$, with no group difference. At 6-months, PWV did not change and was not different between group; exercisers, $923.7 \pm 319.8 \mathrm{~cm} / \mathrm{s}, 905.5 \pm$ 344.7 , controls.

LIMITATIONS: A completion rate of $81 \%$.

CONCLUSIONS: Though exercisers improve fitness and body composition, there were no reductions in BP. The lack of change in arterial stiffness suggests a

Trials Registration clinicaltrials.gov Identifier: NCT00212303

Received December 30, 2011

Revised March 6, 2012

Accepted April 19, 2012

Published online May 19, 2012 resistance to exercise-induced BP reduction in persons with T2DM.

KEY WORDS: exercise training; diabetes; high blood pressure; randomized trial.

J Gen Intern Med 27(11):1453-9

DOI: $10.1007 / \mathrm{s} 11606-012-2103-8$

() Society of General Internal Medicine 2012

\section{INTRODUCTION}

The Framingham Heart Study ${ }^{1,2}$ and the Multiple Risk Factor Intervention Trial ${ }^{3}$ suggest that at any level of BP the risk for a cardiac event is increased in both sexes with impaired glucose tolerance compared with those with normal glucose tolerance. The risk for cardiovascular (CV) events increased linearly in the "normotensive" BP range and extended into the range of BP usually considered "hypertensive." These data suggest that intensive BP lowering in patients with type 2 diabetes (T2DM) would reduce cardiovascular disease (CVD) risk. Pharmacological trials ${ }^{4}$ in persons with T2DM report a reduction of stroke incidence with more intensive therapy using multiple drugs when SBP was reduced to $\leq 120 \mathrm{mmHg}$, but at the expense of increased serious adverse events. Moreover, there are no added benefits for pharmacological therapies on other $\mathrm{CV}$ outcomes, compared to less intensive therapy. These findings underscore a need for treatments that lower BP while avoiding the side effects often associated with antihypertensive drug therapy.

Exercise has been shown to lower BP in persons without T2DM, with few if any side-effects. ${ }^{5}$ Yet, studies on exercise for BP reduction in T2DM have yielded inconsistent results. A 2010 joint position statement from the American College of Sports Medicine (ACSM)/American Diabetes Association (ADA) concluded that "exercise may slightly reduce SBP and reductions in DBP are less common in T2DM". ${ }^{6}$ The report further noted that the 
efficacy of exercise for reducing BP in those with T2DM has not been adequately addressed and rated the evidence for these effects at Level C, due to a lack of randomized controlled trials or meta-analyses.

The SHAPE 2 (Sugar, Hypertension and Physical Exercise) study was a 6-month randomized, controlled trial in persons with T2DM designed to determine the efficacy of supervised exercise on BP, the primary outcome. Secondary outcomes included arterial stiffness, glycemic control, body composition and aerobic and strength fitness.

\section{METHODS}

\section{Setting and Participants}

Participants, aged 40 to 65 years, with T2DM and with untreated suboptimal BP or treated hypertension were recruited primarily through newspaper advertising throughout the greater Baltimore area. Potentially eligible respondents were invited to the Johns Hopkins Bayview Clinical Research Unit (CRU) for screening. Written informed consent was obtained from all participants. The study was approved by the institutional review board at the Johns Hopkins School of Medicine and was conducted between July 2004 and December 2010.

Exclusion criteria included fasting blood glucose $>400 \mathrm{mg} / \mathrm{dl}, \mathrm{HbAlc}>11 \%{ }^{7}$ a history of myocardial infarction, prior coronary artery bypass grafting or coronary angioplasty, chronic heart failure, self-reported substance abuse, co-morbid conditions that would limit the ability to exercise, high degree heart block, smoking, diabetes requiring insulin, and regular participation in moderate to vigorous exercise for $>90$ minutes per week. ${ }^{8}$ Type 2 diabetes was verified with a personal care provider and met the 2003 ADA criteria of fasting glucose $>126 \mathrm{mg} / \mathrm{dl}$, symptoms of hyperglycemia with casual plasma glucose $>200 \mathrm{mg} / \mathrm{dl}$, or two-hour plasma glucose $>200 \mathrm{mg} / \mathrm{dl}$ after a 75 gram oral glucose load. Participants taking oral hypoglycemic medication were eligible, as long as their fasting blood glucose was $<400 \mathrm{mg} / \mathrm{dl}$.

Participants not using antihypertensive medications were required to have SBP between 120 and $159 \mathrm{mmHg}$ or DBP between 85 to $99 \mathrm{mmHg}$ at rest. ${ }^{9}$ Participants being treated with at least one anti-hypertensive medication were eligible, regardless of how low their BP. BP measurements occurred during a two to three week screening phase, at least a week apart. Participants were eligible for the study if the BP was in the described ranges during the first two visits. If the BP on either of these visits fell outside the range, another visit was allowed. The average BP during all of these visits represented the screening $\mathrm{BP}^{10}$

After determining BP eligibility, a maximal graded exercise test ${ }^{10}$ was performed. Exercise test exclusion criteria included $>1 \mathrm{~mm}$ ST-T wave depression, high-grade ventricular arrhythmias, and cardiac symptoms. If the exercise test was positive, the participant was referred to his/her physician. In cases where the physician ordered a follow-up imaging stress test, outside of the study, the participant could continue in the study if the imaging test was negative.

\section{Randomization and Interventions}

Ultimately, 140 participants were randomized to the study groups after baseline testing with equal allocations into each group (Fig. 1).

\section{Exercise Intervention}

Following ACSM guidelines, ${ }^{11}$ exercisers were scheduled to attend three sessions/week which included resistance and aerobic components. The prescribed number of sessions was 78 ( 3 days per week for 26 weeks). Resistance training consisted of 2 sets of seven exercises at 10 to 15 repetitions per exercise at $50 \%$ of 1-repetition maximum on a multistation machine (Hoist 6000; Hoist Fitness, San Diego, CA). When the participant could complete 15 repetitions of an exercise with little difficulty, the weight was increased. Aerobic exercise lasted 45 minutes. Participants were allowed to use a treadmill, stationary cycle, or stairstepper. Heart rate monitors (Polar Inc., Lake Success, NY) were worn, and programmed for a target range of $60 \%$ to $90 \%$ of maximum HR. As fitness improved, the workload was increased to maintain target heart rate levels.

Control Group. Diet, Physical Activity and BP Monitoring. All participants were given "Exercise: A Guide from the National Institute on Aging" (NIH, Bethesda MD). Controls were not offered the supervised exercise. All participants were given dietary guidelines from the American Heart Association before randomization and asked to maintain their usual diet throughout the trial. Dietary data were obtained from 3-day food records and were analyzed using Nutritionist V (First DataBank, San Bruno, CA). No additional dietary advice was provided to any participant. Participants in both groups reported to the CRU monthly for BP monitoring. No further contact with controls occurred during the intervention phase.

\section{Primary Outcome}

Blood pressures were measured by CRU nurses in the right upper arm using an appropriate sized cuff during screening, at the time of randomization, once during each month of the intervention phase, and during final testing using an automated Dinamap MPS Select device (Johnson \& Johnson, 


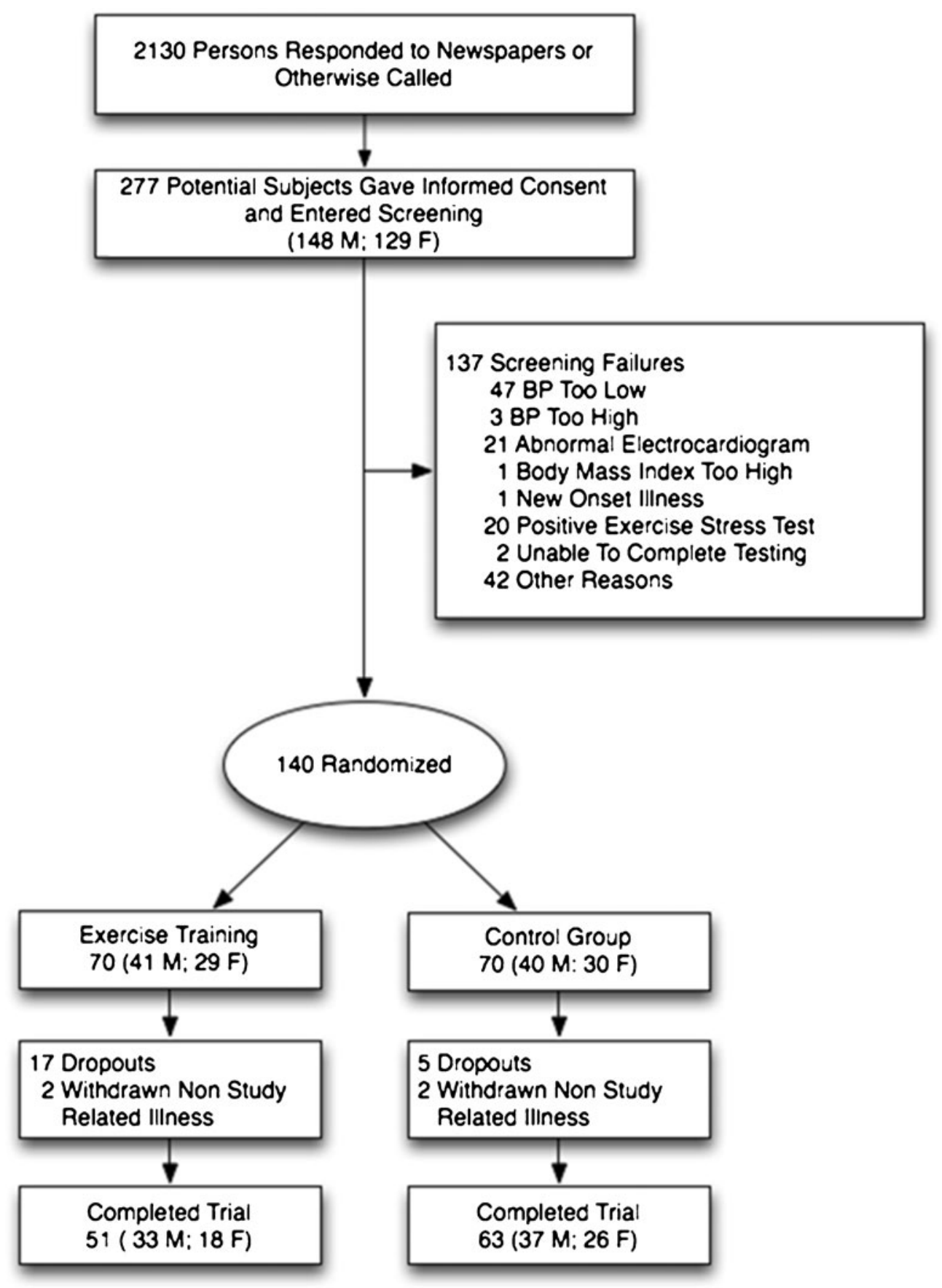

Figure 1. Progress of the participants through the Sugar Hypertension and Physical Exercise (SHAPE2) study. BP indicates blood pressure.

New Brunswick, NJ). The BP device was calibrated every six months. Where possible, the same nurse obtained the BP in each participant. After 5 minutes of sitting at rest, BP was measured three times, with 1 minute between readings. If the BP's differed by more than $5 \mathrm{mmHg}$, additional readings were obtained. The mean of three consecutive readings within $5 \mathrm{mmHg}$ of each other was used as the value for that visit. Baseline BP was the mean of the screening visits plus a BP measurement obtained during baseline testing. Follow-up $\mathrm{BP}$ was the mean of the BP taken during the final month of the intervention phase and the BP taken during the follow-up testing visit.

\section{Secondary Outcomes}

Aortic stiffness was measured by carotid-femoral pulsewave velocity using methods described elsewhere. ${ }^{12}$ Peak oxygen uptake was determined on a treadmill using a Carefusion Vmax 229 Metabolic cart (San Diego, CA). The initial walking speed was $4.8 \mathrm{~km} / \mathrm{h}$ at a grade of $0 \%$, and 
the grade increased by $2.5 \%$ every 3 minutes. Participants were encouraged to reach 18 or higher on the Borg Rating of Perceived Exertion Scale, and they stopped at volitional fatigue. ${ }^{10}$ Muscle strength was assessed by 1-repetition maximum on each of four upper body and three lower body exercises on the Hoist multistation machine. Total strength was the sum of the weights of these seven exercises using methods described previously. ${ }^{10}$

Total fat mass, lean mass, and percentage body fat were assessed by dual energy x-ray absorptiometry (GE Lunar Prodigy, Software Version 13 GE Medical Systems, Milwaukee, WI). Abdominal total, visceral, and subcutaneous fat were measured from images obtained using a magnetic resonance imaging system (Siemens Vision $1.5 \mathrm{~T}$; Siemens Medical systems, Iselin, NJ) following methods described elsewhere. ${ }^{10}$

\section{Statistical Analysis}

Whether exercise reduces BP was tested with a two-group design with repeated measures. Based on our previous study of exercise and $\mathrm{BP},{ }^{10}$ the standard deviation (SD) in each group at baseline was estimated to be $8 \mathrm{mmHg}$ for SBP and $6 \mathrm{mmHg}$ for DBP. It was determined that 60 participants per group would provide $80 \%$ power to detect clinically important reductions of $4.5 \mathrm{mmHg}$ and $3.5 \mathrm{mmHg}$ in SBP and DBP, respectively, with a twosided test and alpha $=0.05$. Thus, we randomized 140 participants, allowing for a dropout rate of $15 \%$. Analyses were performed using STATA version 12 (StataCorp LP, College Station, TX).

Variables were checked for normality and points of influence. Participants characteristics are presented as means (SDs) or as percentages and are compared across groups using independent t-tests or chi-squared tests. Primary outcome analyses used the intention-to-treat principle and included all participants as randomized. Missing outcomes were imputed by chained equations (STATA ice command) using ten imputations for each missing data point. Intervention effects were examined using linear mixed-effects models. Among participants completing baseline and follow-up testing, we calculated Pearson correlation coefficients between changes in BP and changes in diabetes characteristics, fitness and body composition outcomes. The level of statistical significance was set at $\mathrm{P}<$ 0.05 ( 2 tailed).

\section{Role of Funding Source}

Funding was obtained from the National Institute of Diabetes and Digestive and Kidney Diseases, which had no role in the study design, conduct, analysis or interpretation of the data, or the decision to submit the manuscript for publication.

\section{RESULTS}

Figure 1 shows participant flow through the study. Of the 140 randomized participants, 114 completed 6 month testing ( $81 \%)$ and 22 dropped out (17 exercisers, 5 controls); and 2 from each group were withdrawn due to new onset illness not related to the study (cancer, cardiovascular disease with stent placement). No follow-up data are available for those who dropped out or were withdrawn. Exercisers who completed 6 month testing attended a mean 72 of their prescribed 78 sessions (92\%). There were no significant within- or betweengroup differences for change in dietary total kilocalories, macronutrient content, sodium and potassium.

The mean (SD) age of the participants was 56.4 (6.1) years, $42 \%$ were non-white and $70 \%$ were taking at least one anti-hypertensive medication (Table 1). Nineteen

Table 1. Baseline Characteristics of 140 Randomized Participants in the Sugar Hypertension and Physical Exercise (SHAPE2) Study

\begin{tabular}{|c|c|c|c|c|}
\hline Characteristic & $\begin{array}{l}\text { All } \\
(n=140)\end{array}$ & $\begin{array}{l}\text { Exercise } \\
\text { Group } \\
(\mathrm{n}=70)\end{array}$ & $\begin{array}{l}\text { Control } \\
\text { Group } \\
(\mathbf{n}=70)\end{array}$ & $\mathrm{P}^{*}$ \\
\hline Age, years, mean (SD) & $56(6)$ & $57(6)$ & $56(6)$ & 0.097 \\
\hline \multicolumn{5}{|l|}{ Race, No (\%) } \\
\hline $\begin{array}{l}\text { White } \\
\text { Black } \\
\text { Asian } \\
\text { Mixed Race }\end{array}$ & $\begin{array}{c}81(58) \\
55(39) \\
2(1) \\
2(1)\end{array}$ & $\begin{array}{c}39(56) \\
30(43) \\
1(1) \\
0(0)\end{array}$ & $\begin{aligned} 42 & (60) \\
25 & (36) \\
1 & (1) \\
2 & (3)\end{aligned}$ & 0.464 \\
\hline $\begin{array}{l}\text { Use of antihypertensive, } \\
\text { No }(\%)\end{array}$ & $98(70)$ & $52(74)$ & $46(66)$ & 0.268 \\
\hline ACE Inhibitor $\dagger$ & 50 & 31 & 19 & \\
\hline $\begin{array}{l}\text { Angiotensin- } \\
\text { receptor blocker }\end{array}$ & 41 & 20 & 21 & \\
\hline Diuretic & 29 & 15 & 14 & \\
\hline Beta-blocker & 24 & 13 & 11 & \\
\hline $\mathrm{Ca}$ channel blocker & 24 & 16 & 8 & \\
\hline $\begin{array}{l}\text { Aldosterone } \\
\text { receptor blocker }\end{array}$ & 1 & 0 & 1 & \\
\hline $\begin{array}{l}\text { Use of Oral } \\
\text { hypoglycemic } \\
\text { agent, No }(\%)\end{array}$ & $112(80)$ & $55(79)$ & $57(81)$ & 0.673 \\
\hline Metformin & 89 & 48 & 41 & \\
\hline Sulfonylurea & 54 & 24 & 30 & \\
\hline $\begin{array}{l}\text { Thiazolidinedione } \\
\text { (TZD) } \dagger\end{array}$ & 36 & 17 & 19 & \\
\hline $\begin{array}{l}\text { DiPeptidyl Peptidase-4 } \\
\text { Inhibitor }\end{array}$ & 4 & 0 & 4 & \\
\hline Incretin Mimetics & 4 & 2 & 2 & \\
\hline $\begin{array}{l}\text { Use of Lipid } \\
\text { Lowering agent, } \\
\text { No }(\%)\end{array}$ & $81(58)$ & $44(63)$ & $37(53)$ & 0.820 \\
\hline Statins\# & 81 & 44 & 37 & \\
\hline Fibrate & 1 & 0 & 1 & \\
\hline Niacin & 1 & 1 & 1 & \\
\hline \multicolumn{5}{|l|}{$\begin{array}{l}\text { Antihypertensives } \\
\text { prescribed, } \\
\text { No }(\%)\end{array}$} \\
\hline none & $42(30)$ & $18(26)$ & $24(34)$ & 0.333 \\
\hline one medication & $61(44)$ & $30(43)$ & $31(44)$ & \\
\hline two or more & $37(26)$ & $22(32)$ & $15(21)$ & \\
\hline
\end{tabular}

Abbreviations: $S D$, standard deviation; $A C E$, angiotensin converting enzyme

* Test for between group differences

$\dagger$ Four exercisers and three controls discontinued use of a statin; three exercisers and two controls discontinued use of TZD; one control discontinued $A C E$ 
Table 2. Baseline, Follow-up and Change Values for the Primary and Secondary Outcomes with Imputed Values

\begin{tabular}{|c|c|c|c|c|c|c|c|c|c|}
\hline & \multicolumn{4}{|c|}{ Exercise Group } & \multicolumn{5}{|c|}{ Control Group } \\
\hline & $\begin{array}{l}\text { Baseline } \\
(n=70)\end{array}$ & $\begin{array}{l}6 \text { months } \\
(\mathrm{N}=51)\end{array}$ & $\begin{array}{l}\text { Absolute } \\
\text { Change }\end{array}$ & $P^{*}$ & $\begin{array}{l}\text { Baseline } \\
(\mathrm{N}=70)\end{array}$ & $\begin{array}{l}6 \text { months } \\
(\mathrm{N}=63)\end{array}$ & $\begin{array}{l}\text { Absolute } \\
\text { Change }\end{array}$ & $\mathrm{P}^{*}$ & $\mathbf{P} * *$ \\
\hline \multicolumn{10}{|l|}{ Resting Blood Pressure, mean (SE) } \\
\hline Systolic blood pressure, $\mathrm{mm} \mathrm{Hg}$ & $126.9(1.6)$ & $126.5(1.9)$ & $-0.4(1.4)$ & 0.78 & $126.7(1.6)$ & $126.0(1.6)$ & $-0.8(1.2)$ & 0.53 & 0.83 \\
\hline Diastolic blood pressure, $\mathrm{mm} \mathrm{Hg}$ & & & & & & & & 0.59 & 0.30 \\
\hline \multicolumn{10}{|l|}{ Diabetes characteristics } \\
\hline $\mathrm{HbA1c}, \%$ & $6.6(0.2)$ & $6.4(0.2)$ & $-0.2(0.2)$ & 0.29 & $6.7(0.2)$ & $7.0(0.2)$ & $0.3(0.1)$ & 0.03 & 0.03 \\
\hline Glucose, mg/dL & 137.0 & 135 & & 0.7 & 149.9 & 147.9 & -2 . & 0.78 & 0.61 \\
\hline \multicolumn{10}{|l|}{ Aerobic and strength fitness, mean (SE) } \\
\hline Peak oxygen uptake, $\mathrm{ml} / \mathrm{kg} / \mathrm{min}$ & $21.9(0.7)$ & $25.2(0.8)$ & $34(04)$ & $<0.001$ & $22.1(0.7)$ & $22.5(0.8)$ & $0.4(0.4)$ & 0.25 & $<0.001$ \\
\hline Total & $873.3(29.0)$ & 994.4 & 121.1 & $<0.001$ & 925.3 & $911.7(34.3)$ & $-13.7(13.6)$ & 0.32 & $<0.001$ \\
\hline \multicolumn{10}{|l|}{ Body composition, mean (SE) } \\
\hline Body mass index, $\mathrm{kg} / \mathrm{m}^{2}$ & $33.0(0.6)$ & $32.1(0.6)$ & $-0.8(0.2)$ & 0.00 & $33.6(0.5)$ & $33.5(0.5)$ & $-0.1(0.2)$ & 0.48 & 0.01 \\
\hline Weigl & $97401)$ & 952018 & $-2.2(0.6)$ & 0.00 & 99.2( & 987 & -0.6 & 021 & 0.04 \\
\hline imference, $\mathrm{cm}$ & $103.0(1.4)$ & $101.5(1.4)$ & $-1.5(0.5)$ & 0.00 & $104.4(1.2)$ & $104.0(1.2)$ & $-0.4(0.5)$ & 0.43 & 0.10 \\
\hline Abdominal total fat, $\mathrm{cm}^{2}$ & $579.9(19.7)$ & $555.3(18.8)$ & $-26.1(11.1)$ & 0.03 & $597.6(17.5)$ & $592.5(19.1)$ & $-6.3(9.0)$ & 0.49 & 0.16 \\
\hline Abdominal visceral fat, $\mathrm{cm}^{2}$ & $153.3(8.2)$ & $145.0(8.5)$ & $-8.1(5.2)$ & 0.13 & $165.2(8.9)$ & $161.3(8.9)$ & $-2.1(4.6)$ & 0.64 & 0.38 \\
\hline Abdominal subcutaneous fat, $\mathrm{cm}^{2}$ & $399.9(17.1)$ & $381.6(16.0)$ & $-20.0(1.7)$ & 0.01 & $404.7(15.1)$ & $401.4(16.0)$ & $-6.1(1.6)$ & 0.28 & 0.10 \\
\hline Total body fat, $\%$ & $38.2(0.9)$ & $36.6(0.9)$ & $-1.6(0.3)$ & $<0.001$ & $38.4(0.9)$ & $38.4(0.9)$ & $0.0(0.3)$ & 0.86 & $<0.001$ \\
\hline Lean body mass, $\%$ & $58.4(0.9)$ & $60.0(0.9)$ & $1.6(0.3)$ & $<0.001$ & $58.2(0.9)$ & $58.2(0.9)$ & $-0.1(0.3)$ & 0.83 & 0.00 \\
\hline \multicolumn{10}{|l|}{ Vascular stiffness, mean (SE) } \\
\hline Pulse wave velocity, $\mathrm{cm} / \mathrm{s}$ & $922.1(40.1)$ & $929.6(46.5)$ & $7.5(45.4)$ & 0.87 & $909.4(42.8)$ & $910.1(45.4)$ & $0.6(49.6)$ & 0.99 & 0.84 \\
\hline
\end{tabular}

Abbreviations: SE standard error

*Test for difference on change from baseline

**Test for between-group difference on the change from baseline

individuals who were not taking anti-hypertensive medications were above the BP treatment goal for diabetes of $130 / 80 \mathrm{mmHg}{ }^{13}$

Table 2 summarizes selected study outcomes at baseline, 6-months and the absolute change from baseline. No significant reductions in SBP or DBP or pulse wave velocity were observed after 6 months in either group. Separate analyses (not shown) including only participants who completed baseline and follow-up testing yielded similar results to models based on imputation.

At baseline, HbAlc across all participants was 6.7 (1.5) and the mean $\mathrm{VO}_{2 \max }$ was $22.0(5.5) \mathrm{ml} \cdot \mathrm{kg}^{-1} \cdot \mathrm{min}^{-1}$. $\mathrm{HbA} 1 \mathrm{c}$ decreased by $0.2 \%$ in exercisers compared with a $0.3 \%$ increase in controls $(p=0.030)$. Exercisers had greater

Table 3. Pearson Correlation Coefficients for Changes in Blood Pressure vs. Changes in Selected Variables*

\begin{tabular}{lcccc}
\hline \hline Variable & $\begin{array}{l}\text { Change in } \\
\text { Systolic } \\
\text { Blood } \\
\text { Pressure }\end{array}$ & P value & $\begin{array}{l}\text { Change in } \\
\text { Diastolic } \\
\text { Blood } \\
\text { Pressure }\end{array}$ & P value \\
\hline HbA1c & -0.13 & 0.188 & 0.01 & 0.951 \\
Glucose & 0.08 & 0.390 & 0.17 & 0.086 \\
QUICKI & -0.07 & 0.480 & -0.13 & 0.178 \\
Peak oxygen uptake & 0.08 & 0.402 & 0.04 & 0.690 \\
Total muscle strength & -0.16 & 0.082 & -0.14 & 0.126 \\
Weight & 0.06 & 0.510 & -0.02 & 0.810 \\
Waist circumference & 0.12 & 0.213 & 0.06 & 0.535 \\
Abdominal total fat & 0.22 & 0.024 & 0.05 & 0.602 \\
Abdominal & 0.19 & 0.048 & 0.07 & 0.489 \\
subcutaneous fat & & & & \\
Abdominal visceral fat & 0.18 & 0.066 & -0.01 & 0.960 \\
Percent total body fat & 0.00 & 0.999 & 0.05 & 0.602 \\
Percent total lean mass & 0.02 & 0.858 & -0.02 & 0.840 \\
Pulse wave velocity & -0.15 & 0.160 & -0.08 & 0.440
\end{tabular}

*There were 114 participants for each variable except pulse wave velocity $(n=94)$ increases in peak oxygen uptake by $3.0 \mathrm{ml} / \mathrm{kg}$ per minute and total strength by $37.6 \mathrm{~kg}(\mathrm{p}<0.001$ for both). Exercisers lost $2.2 \mathrm{~kg}(\mathrm{p}=0.002)$ of body weight whereas no change was observed for controls. Total body fat fell by $1.8 \%$ more in exercisers versus controls $(\mathrm{p}<0.001)$, whereas exercisers increased lean mass by $2.6 \%$ versus controls $(\mathrm{p}=0.004)$. Total abdominal fat was reduced by $19.8 \mathrm{~cm}^{2}$ more and abdominal subcutaneous fat by $14.1 \mathrm{~cm}^{2}$ more in exercisers versus controls, but these changes fell short of statistical significance $(p=0.156$ and $p=0.100$, respectively). There was no significant change in abdominal visceral fat.

Table 3 shows correlates of change in BP. A decrease in SBP was associated with a decrease in abdominal total fat $(\mathrm{r}=0.22$, $\mathrm{p}=0.024)$ and abdominal subcutaneous fat $(\mathrm{r}=0.19, \mathrm{p}=0.048)$. No correlations of DBP change with other outcomes were significant.

\section{DISCUSSION}

The ACSM and ADA position statement on exercise reported that exercise may slightly reduce SBP and reductions in DBP are less common in persons with T2DM. ${ }^{6}$ The evidence for this statement was rated category $\mathrm{C}$ because of a lack of randomized controlled trials. The key finding in the present randomized controlled trial was no reductions in resting SBP or DBP were achieved among exercisers at 6 months despite a training effect as evidenced by increased fitness, improved glycemic control and improved body composition. Thus, our study provides a higher level of evidence, and corroborates the finding of a recent trial, ${ }^{14}$ supporting the conclusion of ACSM/ADA 
regarding lack of efficacy of exercise for reducing BP in this population.

Several factors might explain the lack of change in BP. First, the metabolic abnormalities associated with diabetes impair vascular function, inhibit vasodilation and augment vasoconstriction, which could contribute to arterial structural remodeling and stiffening, leading to raised systolic BP. ${ }^{15}$ We observed no reduction in aortic stiffness suggesting limited plasticity in diabetic vasculature. One study ${ }^{16}$ reported no change in SBP or aortic stiffness among men with diabetes, but who were not necessarily hypertensive, after 2 years of exercise training. It is possible that adverse vascular changes in persons with diabetes ${ }^{17}$ reflects end organ damage that cannot be reversed with exercise alone. Moreover, while ACE inhibitors and diuretics may improve vessel wall structure, beta blockers may have an opposite effect. ${ }^{18,19}$ Thus, current antihypertensive therapy may differentially affect responses to exercise treatment.

Second, the JNC 7 guidelines ${ }^{9}$ recommend that physicians consider drug therapy, with exercise as an adjunct treatment for elevated BP in T2DM. Consistent with this recommendation, $70 \%$ of our sample was being treated with BP lowering medications at the time of randomization. A goal of the study was to determine the effects of exercise training above and beyond usual care as practiced in the community. Therefore, we recruited participants who were either treated or untreated with antihypertensive medications. Although scientifically it would be more desirable to study persons with untreated hypertension, this was not ethically possible. Thus, our results may be more generalizable to the broad population of persons with diabetes. The generally well-controlled BPs at baseline may reflect a "floor effect", thereby limiting the potential beneficial impact of exercise of this intensity and duration. In a separate regression model we found a non-significant trend that participants above the target treatment goal of 130/ $80 \mathrm{mmHg}$ for diabetes ${ }^{9}$ at baseline were more likely to experience a reduction in SBP at 6 months, regardless of group assignment or current use of antihypertensive medications. Because of multiple BP checks performed throughout the study, there may have been a regression toward the mean and we were not adequately powered to examine subsets of participants based on race, medication use or whether they were above or below target BP goals.

Third, we observed a modest weight loss of approximately $2.1 \%$ of initial body weight among exercisers. Data from the Action for Health in Diabetes Trial, ${ }^{20}$ in which the baseline BP of approximately $129 / 70 \mathrm{mmHg}$ was similar to our study, showed that a diet and exercise intervention produced weight loss of $8.6 \%$ of initial body weight at one year, and reduced SBP and DBP by $5.33 \mathrm{mmHg}$ and $2.92 \mathrm{mmHg}$, respectively. These data, in contrast to our study with minimal weight loss, suggests that the most effective lifestyle approach for BP reduction in persons with diabetes is one that combines exercise with a weight reducing diet. Of note, in a pooled analysis that included control subjects, a reduction in abdominal subcutaneous fat and total abdominal fat, but not total body weight, were associated with a reduction in SBP, suggesting that metabolic changes that result in abdominal fat changes may impact on blood pressure before marked changes in body weight occur.

Despite the lack of BP reduction with the exercise, there was a modest $(0.2 \%)$ reduction in $\mathrm{HbAlc}$ in the exercise group. The importance of this finding is underscored by the fact that our cohort had well-controlled diabetes at baseline (HbAlc $6.7 \%$ ), which highlights the role of exercise for contributing to a potential reduction in the risk of microvascular complications associated with diabetes. While a recent meta-analysis ${ }^{21}$ showed no apparent benefits of intensive glucose lowering with pharmacological treatment for preventing microvascular events, exercise training may confer a protective effect associated with increased glycemic control, which may not result from pharmacological treatment of hyperglycemia. ${ }^{22}$

Exercisers increased aerobic capacity by about 1 metabolic equivalent (MET), a change that is associated with a $15 \%-20 \%$ reduction in CVD mortality risk. ${ }^{23}$ Despite a modest reduction in weight, exercise training reduced the percentage of total body fat, abdominal and subcutaneous fat and increased lean body mass. Yet there was no significant change in abdominal visceral fat, perhaps due to the presence of diabetes, which is associated with disordered fat mobilization from fat storage $\operatorname{sites}^{24}$ or the use of diabetes or antihypertensive medications may limit visceral fat loss. Our results for visceral fat are in apparent contrast to other studies, ${ }^{25,26}$ which have demonstrated that exercise alone, without weight loss, reduced abdominal visceral fat in individuals with diabetes.

This study had several strengths. The participants underwent a rigorous BP screening and comprehensive body composition and fitness assessments. The sample included both men and women with treated and untreated hypertension, who were representative of the racial distribution of our community. The exercise protocol was guideline driven, being based on those of the ACSM. ${ }^{11}$ Also, while BP can be influenced by dietary behaviors we observed no changes in diet over the course of the trial. There are also some limitations. We observed a higher than expected dropout rate among exercisers of $24 \%$. Many participants in the present trial were employed and may have been more susceptible to drop out due to timeconstraints. Also, we showed previously ${ }^{27}$ that persons with T2DM report lower levels of health related quality of life compared to individuals without diabetes, suggesting that they view themselves as being less capable of meeting the demands of the intervention and are therefore more likely to discontinue the program. Though controls received less attention than exercisers, this limitation is less important 
given there was no BP change in either group. In summary, although BP did not decrease, this finding should not dampen the enthusiasm for exercise since it resulted in several important health benefits including improved fitness body composition, and glycemic control.

\section{Acknowledgements:}

Funding Support: This study was supported by grant R01DK62368 from the National Institute of Diabetes and Digestive and Kidney Diseases (Dr. Stewart); and by Grant Number UL1 RR 025005 from the National Center for Research Resources (NCRR), a component of the National Institutes of Health (NIH), and NIH Roadmap for Medical Research. Its contents are solely the responsibility of the authors and do not necessarily represent the official view of NCRR or NIH. Information on NCRR is available at http://www.ncrr.nih.gov/. Information on Re-engineering the Clinical Research Enterprise can be obtained from http://nihroadmap.nih.gov/clinicalresearch/ overview-translational.asp."

Prior Presentations: American Heart Association Annual Meeting 2011, Orlando FL.

Conflict of Interest: The authors declare that they do not have a conflict of interest.

Corresponding Author: Devon A. Dobrosielski, PhD; Department of Medicine, Division of Cardiology, The Johns Hopkins School of Medicine, 4940 Eastern Avenue, Baltimore, MD 21204, USA (email: ddobros1@jhmi.edu).

\section{REFERENCES}

1. Chen G, McAlister FA, Walker RL, Hemmelgarn BR, Campbell NR. Cardiovascular outcomes in Framingham participants with diabetes: the importance of blood pressure. Hypertension. 2011;57(5):891-7.

2. Kannel WB, Wilson PW, Zhang TJ. The epidemiology of impaired glucose tolerance and hypertension. Am Heart J. 1991;121(4 Pt 2):1268-73.

3. Stamler J, Stamler R, Neaton JD. Blood pressure, systolic and diastolic, and cardiovascular risks. US population data. Arch Intern Med. 1993;153(5):598-615.

4. Bangalore S, Kumar S, Lobach I, Messerli FH. Blood pressure targets in subjects with type 2 diabetes mellitus/impaired fasting glucose: observations from traditional and bayesian random-effects metaanalyses of randomized trials. Circulation. 2011;123(24):2799-810.

5. Pescatello LS, Franklin BA, Fagard R, Farquhar WB, Kelley GA, Ray CA, et al. American College of Sports Medicine position stand. Exercise and hypertension. Med Sci Sports Exerc. 2004;36(3):533-53.

6. Colberg SR, Sigal RJ, Fernhall B, Regensteiner JG, Blissmer BJ, Rubin RR, et al. Exercise and type 2 diabetes: the American College of Sports Medicine and the American Diabetes Association: joint position statement executive summary. Diabetes Care. 2010;33 (12):2692-6.

7. Whaley MH, Brubaker PH, Otto RM. ACSM's Guidelines for Exercise Testing and Prescription. 7th ed. Baltimore: Lippincott Williams \& Wilkins; 2006

8. Pate RR, Pratt M, Blair SN, Haskell WL, Macera CA, Bouchard C, et al. Physical activity and public health. A recommendation from the Centers for Disease Control and Prevention and the American College of Sports Medicine. JAMA. 1995;273(5):402-7.
9. Program NHBPE. The Seventh Report of the Joint National Committee on Prevention, Detection, Evaluation, and Treatment of High Blood Pressure (JNC7). 2003:03-5233.

10. Stewart KJ, Bacher AC, Turner KL, Fleg JL, Hees PS, Shapiro EP, et al. Effect of exercise on blood pressure in older persons: a randomized controlled trial. Arch Intern Med. 2005;165(7):756-62.

11. Albright A, Franz M, Hornsby G, Kriska A, Marrero D, Ullrich I, et al. American College of Sports Medicine position stand. Exercise and type 2 diabetes. Med Sci Sports Exerc. 2000;32(7):1345-60.

12. Stewart KJ, Sung J, Silber HA, Fleg JL, Kelemen MD, Turner KL, et al. Exaggerated exercise blood pressure is related to impaired endothelial vasodilator function. Am J Hypertens. 2004;17(4):314-20.

13. Third Report of the National Cholesterol Education Program (NCEP). Expert Panel on Detection, Evaluation, and Treatment of High Blood Cholesterol in Adults (Adult Treatment Panel III) final report. Circulation. 2002; 106(25):3143-421.

14. Sigal RJ, Kenny GP, Boule NG, Wells GA, Prud'homme D, Fortier M, et al. Effects of aerobic training, resistance training, or both on glycemic control in type 2 diabetes: a randomized trial. Ann Intern Med. 2007;147 (6):357-69.

15. Beckman JA, Creager MA, Libby P. Diabetes and atherosclerosis: epidemiology, pathophysiology, and management. JAMA. 2002;287 (19):2570-81

16. Loimaala A, Groundstroem $\mathbf{K}$, Rinne $\mathbf{M}$, Nenonen A, Huhtala $\mathbf{H}$, Parkkari J, et al. Effect of long-term endurance and strength training on metabolic control and arterial elasticity in patients with type 2 diabetes mellitus. Am J Cardiol. 2009;103(7):972-7.

17. Stewart KJ. Exercise training and the cardiovascular consequences of type 2 diabetes and hypertension: plausible mechanisms for improving cardiovascular health. JAMA. 2002;288(13):1622-31.

18. London GM, Asmar RG, O'Rourke MF, Safar ME, Investigators RP. Mechanism(s) of selective systolic blood pressure reduction after a lowdose combination of perindopril/indapamide in hypertensive subjects: comparison with atenolol. J Am Coll Cardiol. 2004;43(1):92-9.

19. Safar ME. Can antihypertensive treatment reverse large-artery stiffening? Curr Hypertens Rep. 2010;12(1):47-51.

20. Wing RR. Long-term effects of a lifestyle intervention on weight and cardiovascular risk factors in individuals with type 2 diabetes mellitus: four-year results of the Look AHEAD trial. Arch Intern Med. 2010;170 (17):1566-75

21. Boussageon $\mathbf{R}$, Bejan-Angoulvant $\mathbf{T}$, Saadatian-Elahi $\mathbf{M}$, Lafont $\mathbf{S}$, Bergeonneau C, Kassai B, et al. Effect of intensive glucose lowering treatment on all cause mortality, cardiovascular death, and microvascular events in type 2 diabetes: meta-analysis of randomised controlled trials. BMJ. 2011;343:d4169.

22. Chudyk A, Petrella RJ. Effects of Exercise on Cardiovascular Risk Factors in Type 2 Diabetes. Diabetes Care. 2011;34(5):1228-37.

23. Kodama S, Saito K, Tanaka S, Maki M, Yachi Y, Asumi M, et al. Cardiorespiratory fitness as a quantitative predictor of all-cause mortality and cardiovascular events in healthy men and women: a metaanalysis. JAMA. 2009;301(19):2024-35.

24. Lewis GF, Carpentier A, Adeli K, Giacca A. Disordered fat storage and mobilization in the pathogenesis of insulin resistance and type 2 diabetes. Endocr Rev. 2002;23(2):201-29.

25. Giannopoulou I, Ploutz-Snyder LL, Carhart R, Weinstock RS, Fernhal $\mathbf{B}$, Goulopoulou S, et al. Exercise is required for visceral fat loss in postmenopausal women with type 2 diabetes. J Clin Endocrinol Metab. 2005;90(3):1511-8

26. Mourier A, Gautier J-F, Kerviler ED, Bigard AX, Villette J-M, Garnier $\mathbf{J}-\mathbf{P}$, et al. Mobilization of Visceral Adipose Tissue Related to the Improvement in Insulin Sensitivity in Response to Physical Training in NIDDM: Effects of branched-chain amino acid supplements. Diabetes Care. 1997;20(3):385-91.

27. Bennett WL, Ouyang $\mathbf{P}, \mathbf{W u}$ AW, Barone BB, Stewart KJ. Fatness and fitness: how do they influence health-related quality of life in type 2 diabetes mellitus? Health Qual Life Outcomes. 2008;6:110. 